\title{
Educación, psicología y coaching: un entramado positivo
}

\section{Education, Psychology and Coaching: A Positive Framework}

\author{
Cristina Sandoval Lentisco \\ cristina_sl89@hotmail.com \\ Olivia López Martínez ${ }^{1}$ \\ Olivia@um.es \\ Universidad de Murcia, España
}

\section{Resumen:}

La psicología positiva está alcanzando un progresivo auge, no solo en el ámbito clínico, sino también en el ámbito educativo. De hecho, podemos encontrar experiencias pioneras en este ámbito donde se afirman las ventajas de una educación basada en la pedagogía de la felicidad (Carpena, 2014). Educar bajo los pilares de la psicología positiva (emociones, fortalezas- virtudes e institución positiva), junto a los elementos que constituyen la teoría del bienestar es esencial para potenciar la resiliencia y minimizar el dolor emocional que se genere a lo largo de la vida. Sin embargo, itodas las prácticas que promueven lo positivo es psicología positiva? En la actualidad existen algunas creencias erróneas sobre su concepto y campo de intervención. En algunos casos, se ha simplificado su teoría asemejándola al pensamiento positivo que abogan algunos manuales de autoayuda. En otras ocasiones, se ha confundido con sesiones de coaching emocional a través de los planes de entrenamiento personal-emocional que ésta promueve. Si nos trasladamos al ámbito educativo, podemos observar

\begin{abstract}
:
Positive Psychology is progressively gaining momentum not only in clinic but also in educational fields. In fact, we can find different pioneering experiences in this field which show the advantages of positive education. An education based on the pillars of positive psychology could and should be applied across all educational levels. However, are all positive practices really Positive Psychology? Nowadays, there are some mistaken beliefs on the concept and its area of influence. In certain cases, its theory has been oversimplified being equated to the type of positive thinking promoted by some self-help manuals. On other occasions, it has been confused with emotional coaching and its personal-training plans. Within the educational field, we can observe how positive psychology intertwines with the theory and practice of emotional education and emotional intelligence. In light of the chaos of opinions and false beliefs in the field of Psychology, we intend to debunk these myths and clarify these concepts for the purpose of facilitating the entrance to schools of a true Positive Psychology.
\end{abstract}

1 Dirección para correspondencia (correspondence address):

Olivia López Martínez. Dpto. de Psicología Evolutiva y de la Educación. Facultad de Educación. Universidad de Murcia. Campus de Espinardo, s/n. 30100 Murcia (España). 
cómo ésta se ha entremezclado con las teorías y prácticas de la educación emocional y la inteligencia emocional. Ante la diversidad de opiniones y creencias erróneas sobre esta rama de la psicología, se propone desmitificar tales mitos, esclarecer dichos conceptos para así abrir paso a la praxis de la verdadera psicología positiva en los centros educativos. Se concluye estableciendo las similitudes y diferencias de estas áreas de trabajo frente la psicología positiva a fin de esclarecer el entramado positivo que nos invade en la actualidad.

\section{Palabras clave:}

Psicología positiva; coaching psicológico positivo; pensamiento positivo; educación emocional; inteligencia emocional.

\section{Key words:}

Positive psychology; positive psychological coaching; positive thinking; emotional education; emotional intelligence.

\section{Resumé:}

La psychologie positive est en plein essor, non seulement dans le domaine clinique, mais aussi dans l'éducation. De fait, nous pouvons trouver des expériences pionnières dans ce domaine où les avantages d'un enseignement basé sur la pédagogie du bonheur (Carpena, 2014) sont établis. Éduquer sous les piliers de la psychologie positive (émotions, les points forts et l'institution positive), ainsi que sous les éléments de la théorie du bien-être est essentiel pour renforcer la résilience et réduire la douleur émotionnelle qui est générée tout au long de la vie. Toutefois, les pratiques qui favorisent le positif sontelles toutes de la psychologie positive? Actuellement, il y a quelques idées fausses sur le concept et le champ d'intervention. Dans certains cas, la théorie a été simplifiée en la comparant à la pensée positive préconisée dans certains manuels d'entraide. À d'autres moments, elle a été confondue avec des séances de coaching émotionnel à travers les plans émotionnels de formation personnelle qu'elle promeut. Si nous passons au domaine de l'éducation, nous pouvons voir comment on la confond avec les théories et les pratiques de la maîtrise émotionnelle et de l'intelligence émotionnelle. Étant donnée la diversité des points de vue et les idées fausses au sujet de cette branche de la psychologie nous proposons de démystifier ces mythes, de clarifier ces concepts afin de faire place à la pratique de la vraie psychologie positive dans les écoles. Nous concluons en identifiant les similitudes et les différences de ces domaines de travail sur la psychologie positive afin de clarifier le cadre positif qui nous envahit aujourd'hui.

\section{Mots clés:}

La psychologie positive; le coaching psychologique positif; la pensée positive; la maîtrise émotionnelle; l'intelligence émotionnelle.

Fecha de recepción: 11-12-2014

Fecha de aceptación: 08-06-2015 


\section{Introducción}

Desde el nacimiento de la psicología positiva con el profesor Seligman, a finales de los años cuando es nombrado presidente de la APA, se ha defendido un nuevo enfoque de estudio del ser humano basado en las emociones positivas y los factores que nos conducen a nuestro bienestar. Esta perspectiva de la psicología ha dejado de centrarse únicamente en las psicopatologías y en el dolor emocional, para abordar cómo mejorar la calidad de las personas. Siguiendo este enfoque y bajo el prisma educativo, la escuela es una institución que va a permitir el desarrollo de dos aspectos esenciales: la sabiduría y la felicidad. Dicha institución es el lugar idóneo para potenciar ambos aspectos. La escuela, además de transmitir habilidades instrumentales, tiene como tarea básica la de enseñar a vivir, a ser felices y sabios en nuestra vida (Moreno y Gálvez, 2010).

Hacer de la psicología positiva una forma de trabajo en las escuelas no solamente es deseable, sino que es posible. De acuerdo, con Carpena (2014) la psicología positiva en nuestras aulas tiene sentido en la medida que se convierte en el elemento de cambio y crecimiento personal. No obstante, deberíamos de empezar por reconsiderar dicho concepto si pretendemos aplicar adecuadamente los principios que ésta promueve en nuestros centros educativos. De hecho, Prieto (2006) manifiesta la falta de claridad de la psicología positiva. Cabanes y Sánchez (2012) en un intento de criticar las potencialidades de la psicología positiva la denominan "Individualismo positivo". Tal y como afirma Vázquez (2013), necesitamos reflexionar acerca de los fundamentos y prácticas de psicología positiva, a fin de ofrecer "una mirada de justicia" a esta rama de la psicología.

Si aludimos al concepto de psicología positiva y de su aplicabilidad educativa, a menudo surgen varios términos erróneos. Si preguntáramos a los docentes sobre si conocen experiencias de psicología positiva a nivel educativo es muy posible que hagan referencia a una clase de coaching o que se aluda al pensamiento positivo como corriente que defienden algunos manuales de autoayuda. Estos manuales, tales como El arte de amargarse la vida (Watzlawick, 2003) o Alas de luz: descubre la magia interior (Forner, 2013) nos ayudarán a alejar los pensamientos negativos y nos ofrecerán una serie de tareas para ir ejercitando.

Otro concepto con el que comúnmente se asocia la psicología posi- 
tiva es con el de educación emocional o incluso con inteligencia emocional. Asimismo, existen artículos científicos que nos hablan de forma conjunta de psicología positiva y de inteligencia emocional como Cuadra- Peralta y otros (2010) o Fernández-Berrocal y Extremera (2009). En esta línea también encontramos libros que llevan por título: Aprende a cambiar tu estado emocional en 15 minutos usando las herramientas del coaching, la inteligencia emocional y programación neurolingüística (Jurado, García y Ruano, 2011). Por tanto, el panorama actual es un tanto confuso y aún más la terminología empleada. Por este motivo, en este artículo se clarifican todos estos términos confusos entre sí, en relación con las ideas de la psicología positiva, a fin de esclarecer el panorama actual.

\section{El coaching: emocional, educativo y positivo}

El coaching ha crecido en gran medida en las tres últimas décadas. Éste nace como proceso de mejora del desempeño individual y pronto se extrapoló al ámbito empresarial y deportivo a través de Gallwey (1972) con su teoría de "El juego interior". Podemos afirmar, como el término coaching se ha incorporado en todos los ámbitos (personal, laboral, social, psicológico y educativo). Sin embargo, existe un denominador común, y es que el coaching se caracteriza por ser un proceso dialógico donde se asume la relación entre coach (experto) y cliente (coachee).

Según Ravier (2009) el coaching es un proceso basado en el diálogo entre dos socios que reflexionan ante unas acciones concretas para alcanzar unos objetivos establecidos. Para su aplicación será necesario determinar las metas, los medios para alcanzarlas y la elaboración de un plan de acción. La metodología empleada está basada en el principio metodológico denominado: CAR (Conciencia, Auto-creencia y Responsabilidad). La conciencia nos permitirá clarificar nuestros fines y medios a utilizar. La auto-creencia, se refiere al convencimiento de uno mismo de que podemos alcanzar tales fines. Finalmente, la responsabilidad a través de la voluntad y la perseverancia, será lo que nos lleve a conseguirlo. En ocasiones, el coaching se ha considerado una herramienta (De la Corte, 2002). Sin embargo, y siguiendo con Ravier (2009) el coaching debe ser visto como un proceso. De este modo, el coaching consiste en un proceso cíclico, marcado por los siguientes pasos: 
1) Conciencia y auto-creencia: se produce la reflexión intrínseca.

2) Conocimiento: único e irrepetible (situación concreta)

3) Responsabilidad: libertad individual

4) Acción: a través del plan de acción acordado entre coach y coachee.

Según estas ideas, nada parece que tengan en común el coaching con la corriente de psicología positiva. Si bien, es cierto que presentan algunos elementos comunes como la autorrealización y la búsqueda de un pensamiento positivo. No obstante, el planteamiento teórico inicial y la metodología son distintas.

En el coaching la relación que existe entre experto (coach) y cliente (coachee) es jerárquica y simétrica, ya que el experto nunca pierde su rol. Es cierto que hablamos de una jerarquía débil, ya que a menudo ambos son vistos como "socios" o "colegas". Recordemos cómo para Ravier (2009), el coaching es un proceso dialógico entre dos socios. Asimismo, Albadalejo (2010) nos afirma que el coaching realiza preguntas a sus clientes y en ningún momento proporciona solución a éste.

Sin embargo, la psicología positiva desde el punto de vista educativo no contempla tal relación entre experto y cliente. En primer lugar y desde el paradigma constructivista, en educación no existen clientes, sino alumnos. El maestro debe ser el mediador de los aprendizajes, debe ser el puente entre el alumno y el conocimiento. Las relaciones que se establecen no son jerárquicas, sino simétricas. Aunque ello, no exime unas normas y un respeto hacia la figura del profesor, al igual que ocurre entre los demás alumnos. En segundo lugar, las relaciones que se establecen en el coaching son uno a uno, mientras que desde el enfoque educativo de la psicología positiva, existen no solo relaciones uno a uno, sino también grupal (el docente dirige su acción con toda la clase) (Carpena y López Martínez, 2012).

Otro factor fundamental y diferenciador es el carácter reactivo (el plan de acción se realiza ante una situación problemática) que presenta el coaching; el problema ya existe, aunque se puede prevenir en situaciones futuras. Sin embargo, la psicología positiva posee carácter proactivo, es decir se interviene antes de que aparezcan los problemas emocionales. Para Prada (2005) se orienta a "realizar intervenciones preventivas que permitan modificar la visión de ser humano que se concibe dentro de la psicología tradicional y de cómo este interactúa con su ambiente". 
Por tanto, el alumno educado desde el enfoque de la psicología positiva, no verá problemas, sino desafíos a los que enfrentarse (Seligman, 2003). Desde este carácter proactivo, se defiende educar al individuo en las emociones desde edades tempranas, ya que las diferentes fluctuaciones que experimentará a lo largo de su vida necesitan de una base de bienestar desde la infancia.

En la actualidad, también existe el concepto de coaching educativo. Autores como Embied (2011) y Bou (2009) consideran el coaching educativo como una herramienta importante para el cambio, que permitirá la orientación para el éxito y ayudará a alcanzar la felicidad, en contraposición a Ravier (2009), quien afirmaba, de forma fehaciente, que no debe ser considerado como herramienta, sino como proceso. Según Embied (2009), define al coaching educativo como:

"el arte de acompañar a aquellas personas que están desarrollándose, creciendo como seres humanos, de una forma efectiva y de bienestar para ellos mismos, a través de la conversación y dándoles el poder de creer en ellos mismos"(citado por García, 2009).

Para Bou (2009), quien define las cualidades de un coach (docente), destaca entre ellas: saber escuchar, ofrecer disponibilidad, ser competente, tener buen ánimo, actitud metal positiva. Sin embargo, estas cualidades se podrían encontrar en cualquier tratado de pedagogía o manual de didácticas general, de cómo ser buen docente (sin necesidad de ser coach). De hecho, Gibson (2009), nos habla de las cualidades del un docente excelente y señala la necesidad de entusiasmo y motivación. De la misma forma, Reina (2009) establece los cuatro pilares básicos del buen docente: la capacidad de gestión en el aula, la adaptación de cambios, dominio de las Tecnologías de la Información y la Comunicación (TIC) y capacidad de autocrítica. Por tanto, se considera que la diferencia entre ser coach y las cualidades para ser un buen maestro no son tan equidistantes.

Quizás, el punto innovador que nos proporciona el coaching educativo, se relaciona más con la necesidad de un proceso de orientación, no sólo a nivel académico, sino también personal. Para dicho proceso de orientación será necesario crear un plan de acción (PA), donde exista la clarificación de unas metas. Pero si examinamos detalladamente estos dos conceptos parecen no ser tan novedosos. De esta manera, en virtud 
de lo anterior, nacen dos preguntas: ¿Los docentes no son, o al menos deben ser orientadores? ¿Cuál es la diferencia entre el diseño de un plan de acción y la programación didáctica de un docente?

En relación a la primera pregunta, de acuerdo al concepto de tutoría la orientación es un proceso inherente al proceso de enseñanzaaprendizaje y debe realizarse en todos los espacios educativos (Lázaro y Asensi, 1990). De hecho, la actual legislación educativa (LOMCE, 2013) enuncia entre los principios y fines la orientación educativa- profesional de los estudiantes. Por tanto la orientación debe de estar implícita en los procesos de enseñanza- aprendizaje.

Respecto a la segunda cuestión, y realizando un símil entre la programación didáctica de un maestro y el plan de acción de un coach educativo, podemos observar como toda programación didáctica posee unos objetivos/ estándares de aprendizaje (metas del plan de acción), una metodología a seguir (investigación del PA) y una temporalización (tiempo del PA). Por ello, el verdadero punto innovador y siguiendo con Embied (2009), es que el coaching educativo tiene como base no prejuzgar, no imponer, conversar, creer y desarrollar las fortalezas de los alumnos en un ambiente motivador.

De acuerdo a los pilares de la psicología positiva y el coaching educativo, podemos encontrar factores congruentes como trabajar las fortalezas de los alumnos junto a las emociones positivas. Sin embargo, el coaching educativo, obvia abordar los afectos negativos de las personas. Los defensores de la psicología positiva, son conscientes de que no existen emociones buenas o malas en un sentido moral, ya que todas (buenas y malas) cumplen una doble función de regulación individual y de comunicación (Avia y Vázquez, 2004).

Esta rama de la psicología nos insiste en la necesidad de abordar las emociones negativas, ya que éstas también nos ofrecen algunos puntos a favor, tales como: desarrollar un pensamiento crítico, invitar a la toma de decisiones y la búsqueda de lo que está "mal" en nuestra vida para eliminarlo (Carr, 2007). De esta forma, la psicología positiva no defiende eliminar esas emociones negativas, sino buscar el equilibrio y el punto óptimo entre emociones positivas y negativas.

Asimismo, la psicología positiva no nos habla de establecer un plan de orientación a nivel de aula. Se defiende la idea de crear instituciones positivas, en nuestro caso centros educativos positivos. Por tanto, el enfoque de la psicología positiva es algo más amplio, no se reduce sólo 
a un espacio concreto (aula), sino a la comunidad educativa: alumnos, familia, profesores, amistades,...

Por otro lado, se han encontrado paralelismos entre el concepto de coaching psicológico positivo (Wesson y Boniwell, 2007 y Biswas-Diener y Dean 2007), y el de psicología positiva. Su confusión no es casual, dado que su praxis se nutre del marco teórico de la psicología positiva. De esta forma, y de acuerdo a la teoría del bienestar que nos propone Seligman (2011) los elementos que intervienen en el bienestar de la persona aluden a: emociones positivas, entrega, relaciones positivas, sentido y logro (PERMA).

De esta forma, la práctica del coaching psicológico positivo toma como referencia dichos elementos y desarrolla su campo de intervención en base a éstos. De hecho, en palabras de Grant (2003) este coaching es una plataforma para poder poner en práctica las potencialidades de la psicología positiva. Su diferencia sólo estribará en la medida en la que éstas se apliquen, dado que la praxis del coaching psicológico positivo seguirá encontrando su práctica los principios del coaching enunciados por Ravier (2009).

A fin de clarificar todo lo expuesto anteriormente se la ha elaborado una tabla donde se recogen las características más sobresalientes del coaching junto a las de la psicología positiva desde la perspectiva educativa.

\section{Tabla 1. Características del coaching frente a la psicología positiva.}

\begin{tabular}{|c|c|}
\hline Coaching & Psicología positiva \\
\hline $\begin{array}{l}\text { - Relación jerárquica } \\
\text { - Dirigido a un cliente (único) } \\
\text { - Carácter reactivo } \\
\text { - En un momento puntual } \\
\text { - } \text { Metodología específica } \\
\text { - Proceso planificado a través de } \\
\text { unos pasos. } \\
\text { - Se desarrolla en un espacio concre- } \\
\text { to } \\
\text { - Empowerment } \\
\text { - Emociones positivas }\end{array}$ & $\begin{array}{ll}\text { - } & \text { Relación simétrica } \\
\text { - } & \text { Dirigido a uno o varios componen- } \\
& \text { tes de la comunidad educativa } \\
& \text { (posibilidad grupal) } \\
\text { - } & \text { Carácter proactivo } \\
\text { - } & \text { A lo largo de la vida } \\
\text { - } & \text { Desde edades tempranas } \\
\text { - } & \text { No posee metodología específica. } \\
\text { - } & \text { No está planificado. } \\
\text { - } & \text { Se ha desarrollar en Instituciones } \\
& \text { positivas } \\
\text { - } & \text { Resiliencia } \\
\text { - } & \text { Emociones positivas y negativas }\end{array}$ \\
\hline
\end{tabular}




\section{El pensamiento positivo: una herramienta de autoayuda}

La psicología positiva coincide en algunos aspectos con el pensamiento positivo, considerada ésta como una corriente de autoayuda. Esta ayuda personal será proporcionada a través de manuales de autoayuda. A pesar de que son distintos aspectos comunes entre ambas disciplinas, también debemos de advertir que existe un gran salto entre ambas concepciones, tal y cómo explicaremos a continuación.

Cabanas y Sánchez (2012) han identificado cinco elementos comunes entre el individualismo positivo y psicología positiva. El primer elemento convergente sería el autocontrol. La persona deberá de tener el control de su propio control y lo conseguirá gracias al pensamiento y a la interpretación subjetiva. En segundo lugar, se encuentra la autodeterminación, el individuo de forma autónoma deberá de luchar por sus intereses. En tercer lugar, se identifica el autoconocimiento, ya que la felicidad empieza por el conocimiento de sí mismo. En cuarto lugar, relaciona con el término de autocultivo. La persona siente necesidad de "nutrirse" a sí misma a través del conocimiento. En último lugar, se hace referencia a la auto-responsabilización, en el camino de la búsqueda de la felicidad (salud, éxito y bienestar) será necesaria la toma de decisiones y la responsabilidad ante las elecciones.

Asociar la psicología positiva exclusivamente a estos cinco términos, es presentar un carácter reduccionista de dicho enfoque. De nuevo, se obvia los pilares de dicha psicología (Emociones, Fortalezas- Virtudes e Instituciones positivas) y se alude a conceptos como: resiliencia, creatividad y flow.

De acuerdo con Manciaux, Vanistendael, Lecomte y Cyrulnik (2001), la resiliencia es entendida como la capacidad de una persona o grupo para seguir proyectándose en el futuro a pesar de acontecimientos desestabilizadores, de condiciones de vida difíciles y de traumas a veces graves (citado por Vera, Carbelo y Vecina, 2006). Así como otros conceptos como la creatividad, entendida como "proceso de ser sensible a los problemas [...], de definir las dificultades e identificar el elemento no válido, de buscar soluciones, de hacer suposiciones [...] comunicar los resultados" (Torrance, 1965). O como el término referido al efecto flow, acuñado por Csikszentmihalyi (1997), referido al estado mental y físico que alcanzan las personas cuando se encuentran sumergidos en una actividad en la que se pierde la noción del tiempo. 
Asimismo, esto manuales de autoayuda se centran en el individuo y se olvidan del tratamiento del ser social, elemento fundamental para la felicidad. Sin embargo, la psicología positiva si contempla las transacciones humanas. De hecho, Vázquez (2013) considera que nunca antes en la psicología se habían introducido tantos términos que tuvieran que ver con el ser social del individuo (vínculos simbólicos con la comunidad) para alcanzar el bienestar humano. Emergen así elementos como amor, gratitud, perdón, o generosidad.

Para algunos autores como Delgado (2014) estos manuales de autoayuda carecen de rigor científico, así como de investigaciones bajo el método empírico, por lo que duda de la calidad científica de ellos. Para este autor los manuales de autoayuda atribuyen los problemas que poseen las personas a causas psicológicas, y se atribuye el fracaso exclusivamente a las acciones de la persona donde se ignora las causas externas. A menudo exponen técnicas y un nuevo pensamiento para mejorar algún aspecto de la vida personal, en este caso los pensamientos negativos, la tristeza o la ansiedad. Normalmente, alientan la búsqueda espiritual e interna, promuevan la limpieza emocional, e incluso enseñan a cómo emprender un negocio exitoso. Abad (2010), nos menciona cómo el exitoso escritor Will Ferguson o la psicóloga Wood, sospechan de la utilidad de la autoayuda.

Sin embargo, la psicología positiva es una rama de la psicología tradicional por lo que se sustenta en un saber científico. La psicología positiva parte de un marco empírico, de un planteamiento, de una metodología específica y presenta un objeto de estudio de estudio concreto acerca del cual se investiga y se establecen conclusiones con rigor (Seligman y Csikszentmihalyi, 2000). Siguiendo a Hervás (2009) considerar a la psicología positiva como ciencia, permite excluir afirmaciones sin apoyo empírico o las conclusiones basadas en el juicio personal de un autor. Por tanto, permite establecer conclusiones precisas que no estén sometidas a sesgos personales, contribuyendo a que se produzca un avance continuo en el desarrollo de la disciplina. De nuevo, queda de manifiesto la disparidad entre el pensamiento positivo y la psicología positiva (ver tabla 2). 
Tabla 2. Pensamiento positivo y psicología positiva.

\begin{tabular}{ll}
\hline Pensamiento positivo & Psicología positiva \\
\hline - No es una ciencia. & - Rama de la psicología \\
- Carece de rigor científico. & - Rigor científico \\
- Énfasis en el individuo & - Énfasis en la transacciones humanas \\
- Fracaso del individuo & - Causas externas no contraladas. \\
- Eliminar emociones negativas. & - Emociones negativas: regulación \\
- Búsqueda espiritual y la limpieza & del individuo \\
emocional. & - Búsqueda del equilibrio emocional \\
\hline
\end{tabular}

\section{Educación emocional}

Respecto al tercer concepto, educación emocional, podemos apreciar también algunas diferencias. Comúnmente, cuando se habla de psicología positiva solemos creer erróneamente cómo ésta es el cuerpo teórico y cómo la educación emocional es la parte práctica de ésta. Es decir, la aplicabilidad de la psicología positiva se traduce en aplicar sesiones donde se trabajen las emociones con nuestros alumnos, sesiones basadas en dichos programas de educación emocional. No obstante, la educación emocional posee su propio marco teórico apoyado en la inteligencia emocional.

No podemos negar que la psicología positiva y la educación emocional coinciden en varios aspectos. De hecho, si observamos los actuales programas de educación emocional existentes (Salvador, 2000; Renom, 2007) y cómo estos se están aplicando en las escuelas, podemos ver cómo existen múltiples puntos en común con la psicología positiva. Si bien, los programas de psicología positiva desarrollados en nuestros país, se encuentran en menor número. Entre ellos, se encuentra el Programa de "Aulas felices" (Arguís, Bolsas, Hernández y Salvador, 2010), o las actividades recapituladas en Aplicaciones Educativas de la Psicología Positiva (Caruana, 2010).

$\mathrm{Si}$ analizamos las características de la educación emocional, podemos ver como tiene un enfoque a lo largo del ciclo vital, dado que ésta debe estar presente desde el nacimiento, durante la educación infantil, primaria, secundaria y superior, así como a lo largo de la vida adulta (Bisquerra y Pérez, 2012). Por tanto, ambas disciplinas coinciden en que son un proceso continuo y permanente (enfoque del ciclo vital). De igual forma, tanto la una como la otra presentan un carácter preventivo, 
ya que se defiende el tratamiento de las emociones antes de que aparezcan los problemas emocionales. Sin embargo, la educación emocional se define como un proceso educativo Bisquerra (2001), mientras que la psicología positiva defiende que es un proceso educable, pues no lo limita únicamente al ámbito educativo, sino también al ámbito familiar, social y personal (Carpena, 2014).

Ambas teorías remiten a la búsqueda del bienestar emocional (Seligman, 2011 y Bizquerra, 2001) y se apoyan en conceptos como resiliencia. Este concepto no nace bajo el seno de ninguna de estas dos disciplinas, ya que aparece en el campo de la psicopatología. Sin embargo, ni Bisquerra (educación emocional) ni Seligman (psicología positiva) dudan en incluir las aportaciones de este concepto como marco téorico de sus ideas, respectivamente, Bisquerra (2005), considera la resiliencia como un factor esencial de la regulación emocional. Del mismo modo, Seligman y Csikszentmihalyi (2000) admiten como la resiliencia se relaciona con la capacidad de afrontamiento para adaptarse adecuadamente a diferentes circunstancias y a situaciones adversas. Destacar como se pueden apreciar leves diferencias sobre este término desde un campo y otro, ya que ponen el énfasis en aspectos distintos.

Otro elemento que poseen en común dichas disciplinas, es la incorporación del efecto de flow. Desde la educación emocional se alude al sentimiento de regocijo, de alegría o felicidad convirtiéndose en un referente de cómo nos gustaría que fuese nuestra vida. Asimismo, desde la psicología positiva (Csikszentmihalyi 1998 y Vecina, 2006), se considera la resiliencia como el estado emocional positivo que se experimenta en momentos en los que se encuentran totalmente implicados cuando se están realizando tareas.

Otra coincidencia entre ambas teorías, reside en la voluntad de abordar las emociones de los niños. De acuerdo con Bisquerra (2003), la palabra clave de la educación emocional es emoción, mientras que aprender a gestionar las emociones es otro de los pilares de la psicología positiva.

La educación emocional, según Bisquerra (2009) trabaja la conciencia emocional (cómo me siento yo), regulación emocional (aprender a controlarme), autogestión (qué estrategias debo de utilizar para gestionar adecuadamente y por mi mismo el logro de mis objetivos), inteligencia interpersonal (empatía), habilidades de vida (resolución de conflictos) y bienestar (sentirse bien). De acuerdo con Bisquerra (2009), señalar 
como tratamiento de las emociones procede de la fundamentación de las teorías de las emociones que se remontan a Darwin, James o Cannon, junto al concepto de inteligencias múltiples propuesto por Gardner y el constructo de inteligencia emocional por Salovey y Mayer (1990). Este último término hace referencia a la capacidad de conocer en primer lugar las emociones para manejarlas de forma eficaz, además incide en la motivación de uno mismo y alude a la capacidad de reconocer las emociones de los demás (empatía), junto al arte de establecer relaciones.

Tanto la psicología positiva como la educación emocional, coinciden en tratar las emociones positivas de los niños. Sin embargo, la psicología positiva no estudia únicamente las emociones positivas, bienestar y felicidad sino también aquellos afectos negativos. Tal y como indicábamos al comienzo y siguiendo a Carr (2007), el tratamiento de emociones negativas es indispensable. De hecho, Seligman (2000), proporciona una nueva técnica para desarrollar el optimismo de la persona, la cual parte de los pensamientos negativos. Dicha técnica consiste en empezar a reconocer nuestros propios pensamientos catastróficos y disputar con ellos como si vinieran de una tercera persona.

Por tanto, desde el enfoque de la psicología positiva se hace imprescindible no obviar el pensamiento negativo, ya que a través de su análisis pueden ser el camino hacia el optimismo y nuestro bienestar. Incluso estudios experimentales, realizados por Andrews y Thomson (2009) revelan como cierto nivel de tristeza (siempre que no sea intensa o continuada), puede inducir un razonamiento más analítico. Emociones positivas y negativas constituyen nuestro ser y son necesarias para la construcción de la persona debiendo estar en equilibrio constante. Coincidiendo con Hervás (2009) es totalmente desenfocado reducir la psicología positiva únicamente al tratamiento de las emociones positivas o del bienestar.

Desde la psicología positiva, la creatividad también cobra un rol fundamental, puesto que éste se convierte en un recurso de primer orden para afrontar las circunstancias más adversas (Poseck, 2006; Vecina, 2006). Mientras que en la educación emocional la creatividad es trabajada desde un segundo plano, pues enfatiza otros temas como las habilidades sociales o la empatía (términos no excluidos en el campo de intervención de la psicología positiva).

En la tabla 3, se muestran las diferencias que se han establecido entre la psicología positiva y la educación emocional. 
Tabla 3. Educación emocional y psicología positiva.

\begin{tabular}{ll}
\hline Educación emocional & Psicología positiva \\
\hline - Proceso continuo y permanentecon & - Proceso continuo y permanente con \\
carácter educativo. & carácter educable. \\
- Gestión de las emociones & - Emociones positivas y negativas \\
- Empatía & - Creatividad \\
- Resiliencia = regulación emocional & - Resiliencia $=$ afrontamiento \\
- Competencias emocionales & - Fortalezas y virtudes (Peterson y \\
& Seligman) \\
\hline
\end{tabular}

La psicología positiva va más allá que una educación emocional. Sin embargo, la virtud de la educación emocional radica en que se ha sabido extrapolar el marco teórico a la práctica educativa. Son muchos los centros educativos que son conscientes de la importancia de una educación emocional y han sabido adaptarse a los nuevos tiempos. Sin embargo, la psicología positiva cuenta con una gran escasez de prácticas escolares. Transportar sus potencialidades a la praxis docente es una tarea aún por hacer. Lamentablemente, apenas existen experiencias sobre la aplicación de esta rama de la psicología en los actuales centros educativos.

A lo largo del presente trabajo se han analizado cuatro ámbitos de intervención con sus diferencias y sus similitudes. A continuación, se ofrece un resumen sobre todas las características mencionadas sobre cada ámbito, así como sus rasgos más sobresalientes y objeto de estudio. Además se señala la finalidad que persigue cada disciplina. 
Tabla 4. Características de la psicología positiva frente a otros ámbitos de intervención.

\begin{tabular}{|c|c|c|c|}
\hline Psicología positiva & Coaching & $\begin{array}{c}\text { Pensamiento } \\
\text { positivo }\end{array}$ & $\begin{array}{c}\text { Educación emo- } \\
\text { cional }\end{array}$ \\
\hline $\begin{array}{l}\text { - Rama de la Psicolo- - } \\
\text { gía Humanista. } \\
\text { - Carácter proactivo. } \\
\text { - Enfoque a lo largo } \\
\text { del ciclo vital. } \\
\text { - Proceso educable. - } \\
\text { - Emocionespositivas } \\
\text { y negativas. } \\
\text { - Fortalezas y virtu- - } \\
\text { des. } \\
\text { - Instituciones posi- - } \\
\text { tivas (familia, es- } \\
\text { cuela, social,..). } \\
\text { - Vinculación con la - } \\
\text { comunidad. } \\
\text { - Flow: sentimiento } \\
\text { positivo ante una } \\
\text { tarea donde el } \\
\text { tiempo se } \\
\text { - Resiliencia: capa- } \\
\text { cidad de afronta- - } \\
\text { miento ante situa- } \\
\text { ciones adveras. } \\
\text { Creatividad. }\end{array}$ & $\begin{array}{l}\text { Carácterreactivo. - } \\
\text { En un momento } \\
\text { determinado y - } \\
\text { puntual. (Revier, } \\
\text { 2009). } \\
\text { Relación dialógi- } \\
\text { ca entre experto - } \\
\text { y cliente. } \\
\text { Relación jerár- } \\
\text { quica débil. } \\
\text { Consecución de - } \\
\text { unas metas pla- } \\
\text { nificadas. } \\
\text { Importancia de } \\
\text { establecer un - } \\
\text { plan de acción } \\
\text { para alcanzar } \\
\text { las metas. } \\
\text { Emociones posi- } \\
\text { tivas } \\
\text { Conciencia y au- } \\
\text { tocreencia } \\
\text { Empowerment } \\
\text { Responsabilidad. }\end{array}$ & $\begin{array}{l}\text { Carece de ri- - } \\
\text { gor científico. } \\
\text { Carácter reac- } \\
\text { tivo. } \\
\text { Emocionespo- } \\
\text { sitivas. } \\
\text { F e l i c i d a d } \\
\text { como causa - } \\
\text { interna de la } \\
\text { persona. } \\
\text { El fracaso des- } \\
\text { de el punto - } \\
\text { de vista del } \\
\text { individuo. } \\
\text { Pretende que } \\
\text { la persona - } \\
\text { se auto-con- } \\
\text { trole y se res- - } \\
\text { ponsabilice - } \\
\text { de las elec- - } \\
\text { ciones. }\end{array}$ & $\begin{array}{l}\text { Parte de la teoría } \\
\text { de las emocio- } \\
\text { nes y el concep- } \\
\text { to de Inteligen- } \\
\text { cia emocional. } \\
\text { Carácter proacti- } \\
\text { vo. } \\
\text { Enfoque a lo lar- } \\
\text { go la vida. } \\
\text { Proceso educati- } \\
\text { vo. } \\
\text { Aborda el trata- } \\
\text { miento de las } \\
\text { emociones po- } \\
\text { sitivas. } \\
\text { Habilidades so- } \\
\text { ciales. } \\
\text { Empatía. } \\
\text { Conciencia } \\
\text { Resiliencia: im- } \\
\text { prescindible } \\
\text { para la regula- } \\
\text { ción emocional. }\end{array}$ \\
\hline \multicolumn{4}{|c|}{ FINALIDAD } \\
\hline $\begin{array}{l}\text { - Equilibrio óptimo - } \\
\text { de las emociones } \\
\text { positivas y negati- } \\
\text { vas. } \\
\text { - Fortalezas y virtu- } \\
\text { des son operativas. } \\
\text { - La felicidad es me- } \\
\text { dida a través de la } \\
\text { satisfacción con la } \\
\text { vida. } \\
\text { - Búsqueda del bien- } \\
\text { estar. }\end{array}$ & $\begin{array}{l}\text { Autorrealización - } \\
\text { a través del } \\
\text { cumplimiento } \\
\text { de metas plani- } \\
\text { ficadas. }\end{array}$ & $\begin{array}{l}\text { Búsqueda es-- } \\
\text { piritual y } \\
\text { la limpieza } \\
\text { emocional. }\end{array}$ & $\begin{array}{l}\text { Tratamiento de } \\
\text { las emociones } \\
\text { y gestión eficaz } \\
\text { de las mismas. }\end{array}$ \\
\hline
\end{tabular}




\section{Conclusiones}

A lo largo de este trabajo se ha descrito la psicología positiva como una rama "novedosa" de la psicología tradicional y las potencialidades que ésta nos presenta. Advertir, por tanto, que la psicología positiva no pretende reemplazar a la psicología tradicional, sino complementarla (Park, Peterson, y Sun, 2013), a fin de favorecer el bienestar y el equilibrio emocional del individuo.

Psicología positiva convive actualmente con otras disciplinas que tienen de alguna manera un mismo fin en común: el bienestar del individuo. Es por este motivo que coaching (educativo, psicológico positivo), pensamiento positivo, educación emocional y psicología positiva presentan algunos elementos comunes como son la autorrealización, la búsqueda de la felicidad y la satisfacción personal. Tal y como hemos comprobado a pesar de sus convergencias son conceptos diferentes, por lo que cada una presenta unas ventajas e inconvenientes y una metodología de intervención. Podemos concluir, diciendo que no hay una disciplina realmente válida. Dichas disciplinas aplicadas en un momento adecuado (lugar y tiempo) y bajo la supervisión de un especialista (profesional cualificado), serán igualmente válidas dependiendo del objetivo que queramos alcanzar.

Las experiencias de coaching no son novedosas, pero su aporte al ámbito educativo, si es más reciente, empezando a cobrar fuerza e identificándose las primeras experiencias en nuestros centros educativos, Embied (2011.)Del mismo modo, somos conscientes como la educación emocional posee un gran número de experiencias exitosas en las aulas de educación infantil y primaria desde Salovey y Mayer (1990) y continuando con Goleman (1996). Desde entonces las aportaciones de la educación emocional en el seno escolar han ido proliferando, teniendo éstas un gran prestigio internacional. Sin embargo, en relación a las experiencias de psicología positiva en el ámbito educativo son escasas. Es una disciplina aún en construcción. Serán las experiencias futuras las que permitan seguir consolidando esta reciente rama de la psicología. Es por tanto, un camino aun por hacer, ya que educar bajo el prisma de la psicología positiva es posible.

La escuela como institución positiva, se convierte en un espacio esencial para abordar los aspectos emocionales de los niños, así como las fortalezas y virtudes que componen sus rasgos de personalidad. Dichos 
rasgos de personalidad, empezarán a forjarse en las primeras edades, de ahí, el valor de una educación desde edades tempranas basada en los principios de la psicología positiva. A su vez, estos rasgos nos acompañarán en nuestra vida adulta y serán los responsables de ayudarnos a superar las adversidades que se nos presenten a lo largo de la vida. Tal y como nos indica Carr (2007), la felicidad es un entramado complejo donde intervienen diversas variables, por lo que no existe una receta mágica. Sin embargo, la escuela tiene a su alcance gran cantidad de ingredientes con los que puede ayudar a los niños a la construcción de su bienestar presente y futuro. Por este motivo, se hace esencial una educación positiva en y para la vida.

Para futuras investigaciones en el ámbito del desarrollo emocional positivo y construcción de rasgos de personalidad positivo, bien sea en contextos escolares, familiares como en contextos sociales, se considera que se deben de tener en cuenta los propios marcos de cada disciplina, ya que no toda práctica "positiva" se constituye dentro del marco de la psicología positiva.

\section{Referencias bibliográficas}

Abad, A. (2010, 31 de octubre). El fiasco de los libros de autoayuda: ¿felicidad rápida o un timo para perdedores? El confidencial. El diario de los lectores influyentes Recuperado el 5 de mayo de 2014 desde http://www.elconfidencial.com.

Albadalejo, M. (2010). Coaching y competencias emocionales, Padres y Maestros, 334, 10-14. Recuperado el 12 de marzo de 2014 desde www.encuentropractico.com/ pdf10/competencia-emocional.pdf

Andrews, P.W., y Thomson, J.A. (2009). The bright side of being blue: depression as an adaptation for analyzings complex problems. Psychological Review, 116, 620-654.

Arguís, R.; Bolsas, A.P.; Hernández, S. y Salvador, M.M. (2010). Programa "Aulas felices». Psicología positiva aplicada a la educación. Recuperado el 12 de junio de 2014 desde http://catedu.es/psicologiapositiva/.

Avia, M. D. y Vázquez, C. (2004). Optimismo inteligente. Psicología de las emociones. Madrid: Alianza Editorial.

Bisquerra, R. (2001). Educación emocional y bienestar. Barcelona: Praxis-Wolters Kluwer.

Bisquerra, R. (2003). Educación emocional y competencias básicas para la vida. Revista de Investigación Educativa, 21 (1), 7-43.

Bisquerra, R. (2005). La educación emocional en la formación del profesorado. Revista Interuniversitaria de Formación del Profesorado, 19 (3), 95-114.

Bisquerra, R. (2009). Psicopedagogía de las emociones. Madrid: Síntesis.

Bisquerra, R. y Pérez, N, (2012). Educación emocional: estrategias para su puesta 
Educación, psicología y coaching: un entramado positivo

en práctica. Revista de la Asociación de Inspectores de Educación de España, 16, $1-12$.

Biswas-Diener, R y Dean, B. (2007). Positive Psychology Coaching: Putting the Science of Happiness to Work for your Clients. Unites States of America: Wiley.

Bou, F. (2009). Coaching para docentes: El desarrollo de habilidades en el aula. Alicante: Editorail Club Universitario.

Cabanas E. y Sánchez J. C. (2012). Las raíces de la psicología positiva. Papeles del Psicólogo, 33 (3), 172-182

Carpena, A y López, O. (2012). Emociones positivas creatividad y problemas salud aula. Navarra: Eunsa.

Carpena, A. (2014). Creatividad y emociones positivas en Educación Primaria. Tesis Doctoral. Universidad de Murcia: Murcia.

Carr, A. (2007). Psicología positiva: la ciencia de la felicidad. Barcelona. Paidós.

Caruana, A. (2010). Aplicaciones Educativas de la Psicología Positiva. Generalitat Valenciana: Conselleria d'Educació.

Csikszentmihalyi, M. (1997). Fluir (flow): Una psicología de la felicidad. Barcelona: Kairós.

Csikszentmihalyi, M. (1998). Aprender a fluir. Barcelona: Kairós.

Cuadra-Peralta, A.; Moya- Rubio, Y.; Reyes, L. y Vilca J. (2010). Efecto de un programa de psicología positiva e inteligencia emocional sobre la satisfacción laboral y vital. Revista salud \& sociedad, 1 (2), $101-112$.

De la Corte, J. (2002). La figura del "coaching" en el ámbito laboral. Derecho y conocimiento, 2, 269-284.

Delgado, E. (2014). Los libros de autoayuda. Navarra: Laetoli. Colección ¡Vaya timo!

Embid, A. (2011). La contribución del coaching en la educación. Monográfico de Educaweb,227. Recuperado 12 de junio de 2014 desde http://www.educaweb.com/noticia/2011/03/14/contribucion-coaching-educacion-4668/

Fernández-Berrocal, P. y Extremera, N. (2009). La Inteligencia Emocional y el estudio de la felicidad. Revista Interuniversitaria de Formación del Profesorado, 66, 66-108.

Forner, R. (2013). Alas de luz: descubre la magia interior. Barcelona: Grupo Planeta.

Gallwey, W. T. (1972). El juego interior del tenis. Málaga: Editorial Sirio.

García, L. (2010).Entrevista a la experta en Coaching Educativo, Ana Embid. Recuperado el 3 de junio de 2014 desde http://www.elartedelamemoria.org/2010/02/24/entrevista-a-la-experta-en-coaching-educativo-ana-embid/

Gardner, H. (1995). Inteligencias múltiples. La teoría en la práctica. Barcelona: Paidós.

Gibson, J. (2009). Cualidades de un docente excelente. Revista de Educación en Ciencias de la Salud, 6 (1), 51.

Goleman, D. (1996). Inteligencia emocional. Barcelona: Kairós.

Grant, A. (2003). The impact of life coaching on goal attainment, metacognition and mental health. Social Behavior and Personality: an international journal, 31 (3), 253263.

Hervás, G. (2009). Psicología positiva: una introducción. Revista Interuniversitaria de Formación del Profesorado, 66, 23- 41.

Jurado E., García B. y Ruano, A. Aprende a cambiar tu estado emocional en 15 minu- 
tos usando las herramientas del coaching, la inteligencia emocional y programación neurolingüística, [en línea]. Disponible en: http://www.inselaformacion.com/web/ wpcontent/ploads/2011/04/aprende_a_cambiar_tu_estado_emocional_en_15_minutos.doc.pdf

Lázaro, A. y Asensi, J. (1990). Manual de orientación escolar y tutoría. Madrid. Narcea.

Ley Orgánica 8/2013, de 9 de diciembre, para la mejora de la calidad educativa.

Moreno, B. y Gálvez, M. (2010). La Psicología Positiva va a la Escuela. Típica, Boletín Electrónico de Salud Escolar, 6 (1), 210-220.

Park, N. Peterson, C. y. Sun J. K. (2013). La Psicología Positiva: Investigación y aplicaciones. Terapia psicológica, 31,1. Recuperado el 6 de julio de 2014 desde http://dx.doi. org/10.4067/S0718-48082013000100002

Prada, E. (2005). Psicología positiva y emociones positivas. Revista electrónica Psicología Positiva.com. Recuperado el 20 de mayo del 2014 de http://www.psicologia-positiva. com/Psicologiapos.pdf

Prieto, M. (2006). Psicología Positiva: una moda polémica. Revista Clínica y Salud, 17 (3), 319- 338.

Ravier, L. (2009). Matriz de creatividad y urgencia para definir cuándo y porqué contratar un coach organizacional. En Actas IV Jornadas Internacionales Mentoring y Coaching: Universidad - Empresa (258-272). Madrid: Fundación Rogelio Segovia para el Desarrollo de las Telecomunicaciones.

Reina, J. (2009). Los cuatro pilares básicos del buen docente. Revista de Innovación y experiencias educativas, 20. Recuperado el 12 de junio de 2014 desde http://www. csi-csif.es/

Renom, A. (2007). Educación emocional: programa para educación primaria (6-12 años). Madrid: wolters kluwer.

Salovey, P. y Mayer, J.D. (1990). Emotional intelligence. Imagination, Cognition, and Personality, 9, 185-211

Salvador, M. (2000). Programa de desarrollo emocional. Málaga: Aljibe.

Seligman, M. (2000). Positive Psychology, Positive Prevention, an Positive Therapy, en C. R. Snyder y S.J. López (Eds), Handbook of Positive (3-9). Nueva York: Oxford University Press.

Seligman, M. (2002). La auténtica felicidad. Barcelona: Ediciones B.

Seligman, M. (2003). Positive Psychology: Fundamental Assumptions, Psychologist, 16, 126-127.

Seligman, M. (2011). La vida que florece. Barcelona: Ediciones B.

Seligman, M. y Csikszentmihalyi, M. (2000). Positive Psychology: An Introduction. American Psychologist, 55, 5-14.

Torrance, E.P. (1965). Rewarding creative Behavior. Englewood Cliffs- NJ: Prentice-Hall.

Vázquez, C. (2013). La psicología positiva y sus enemigos: una réplica en base a la evidencia científica. Papeles del Psicólogo, 34 (2), 91-115.

Vecina, M.L. (2006).Emociones Positivas. Papeles del Psicólogo, 27 (1), 9-17

Vera, B. (2006). Psicología positiva: Una nueva forma de entender la psicología. Papeles del Psicólogo, 17, 3-8. 
Educación, psicología y coaching: un entramado positivo

Cristina Sandoval Lentisco y Olivia lópez Martínez

Vera, B, Carbelo, B. y Vecina, M.L. (2006). La experiencia traumática desde la psicología positiva: resiliencia y crecimiento postraumático. Papeles del Psicólogo, 27(1), 40-49. Watzlawick, P. (2003). El arte de amargarse la vida. Barcelona: Herder.

Wesson, K y Boniwell, I.(2007). Flow theory - its application to coaching psychology. En 2nd International Congress of Coaching Psychology (33- 43). England: BPS Shop. 